\title{
ADHERENCE AND QUALITY OF LIFE IN PATIENTS WITH TYPE II DIABETES MELLITUS IN NORTHERN GREECE
}

\author{
Efrosini Zioga1, Kyriakos Kazakos², Evagelos Dimopoulos ${ }^{3}$, Christos Koutras', Kalliopi \\ Marmara ${ }^{4}$, Eleni-Efrosini Marmara ${ }^{5}$, Athanasios Marmaras $^{6}$, Maria Lavdaniti $^{2}$ \\ ${ }^{1}$ General Hospital Imathias-Veria, Veria, Greece \\ ${ }^{2}$ Faculty of Nursing, Alexander Technological Educational Institute of Thessaloniki, Thessaloniki, Greece \\ ${ }^{3}$ Faculty Of Financial Studies, University of Macedonia, Thessaloniki,Greece \\ ${ }^{4}$ Faculty of Physical Education, Aristotele University of Thessaloniki,Thessaloniki,Greece \\ ${ }^{5}$ Faculty of Philology, Aristotele University of Thessaloniki,Thessaloniki,Greece \\ ${ }^{6}$ Physiotherapy Department, Metropolitan College - UEL of Thessaloniki,Thessaloniki,Greece
}

Correspondence author: Maria Lavdaniti, Associate Professor, Alexander Technological Educational Institute of Thessaloniki, Greece, E-mail: maria_lavdaniti@yahoo.gr

\begin{abstract}
Introduction: Adherence as a concept includes various types of health-related behavior. Better medical adherence leads to improved disease control and fewer diabetes-related complications. Quality of life and medication adherence are interrelated. Patients with diabetes who adhere to their treatment can experience an improvement in quality of life and vice versa. Aim: To assess treatment adherence in patients with type II diabetes, as well as the connection between adherence and quality of life. Methodology: A descriptive non-experimental study was conducted in a provincial hospital in Northern Greece. The sample examined was a convenience sample consisting of 108 patients with type II diabetes mellitus. They completed the "Diabetes Self-Care Activities Questionnaire" and SF-36 "Quality of Life Questionnaire". Results: Participants demonstrated good adherence to diet and blood test / blood glucose test routines, but did not experience high levels of quality of life. The type of treatment affected the adherence to blood tests with a statistically significant difference $(p=0,000)$. Also, marital status affected mental health with a statistically significant difference $(p=0,032)$. The adherence sub scales are correlated with the all domains of quality of life. Conclusions: According to our findings, it is important to plan interventions to enhance adherence to other types of treatment and to help patients to further improve their quality of life.
\end{abstract}

Key words: adherence, diabetes mellitus, quality of life, Greece.

\section{INTRODUCTION}

Diabetes mellitus is a common metabolic disease and is classified as a public health problem due to its high incidence and prevalence $(1,2)$. It has been estimated that almost 56 million people have diabetes in Europe - resulting in an estimated prevalence of $8.5 \%$. In Greece, it is estimated that the prevalence of type 2 diabetes is $4.11 \%$ in persons aged $20-70$ years (3). The World Health Organization has predicted that diabetes is going to become the 7th most significant leading cause of death worldwide by the year 2030 (2).

Adherence as a concept includes various types of healthrelated behavior and is not just about taking prescribed medication. According to the WHO, adherence is defined as "the extent to which the patient follows medical instructions" (4). It is reported that better medical adherence leads to improving disease control, fewer cases of diabetes -related complications (such as vascular retinopathy, kidney disease, etc.) (5). Diabetes management is a demanding, lifelong process and requires great effort (6). As a result, medical adherence is essential for diabetes patients in order to minimize serious complications. Studies show that the prevalence of poor adherence to treatment regimens (e.g. medication, diet, exercise etc.) is approximately $36-93 \%$ (7). Diabetes treatment is targeted at improving glycaemia symptoms, reducing the occurrence of diabetes-related complications and ultimately improving patients' quality of life (8).

Quality of life is a concept that relates satisfaction and well-being in the physical, psychological, cultural and socioeconomic spheres (1). The WHO defines quality of life "as individuals' perception of their position in life in the context 
of the culture and value systems in which they live and in relation to their goals, expectations, standards and concerns. It is a broad ranging concept affected in a complex way by the person's physical health, psychological state, level of independence, social relationships, personal beliefs and their relationship to salient features of their environment" (9).

Several studies have shown that there are many factors affecting the adherence to treatment regimens. Some of these are depression $(10,11)$, lack of social support (12), weight loss and glycemic control (13), low literacy levels, forgetfulness, the high cost of medication, limited access to care, complexity of regimens, poor patient-provider communication, and lack of trust in the health-care provider (10). Other factors have been mentioned in studies as well, such as fear of side effects, visual impairment, diabetic foot problems and physicians' attitudes (5).

Quality of life and medication adherence are interrelated in the literature on diabetes. It has been reported that patients with chronic diseases such as diabetes who adhere to their treatment may experience improvement in quality of life and vice versa (14). The relationship between quality of life and treatment adherence is well - documented in the corresponding literature, but the results of many studies are contradictory. Some studies have shown that good quality of life is related to good adherence to diabetes treatment (15, $16,17)$; however, other studies have not demonstrated this link (18). Some authors have suggested that this discrepancy may be due to the difference in tools used to measure treatment adherence (18).

To the best of our knowledge, very few studies have been conducted on adherence and quality of life in Greek diabetes patients. Therefore seemed important to investigate these two parameters.

The aim of this study was to assess treatment adherence in patients with diabetes, type II, as well as the link between adherence and quality of life.

\section{METHODS}

\section{Setting and Sample}

This study is descriptive and non-experimental. It was conducted in the Northern Greek Provincial Hospital of Veria. The sample examined was a convenience sample and consisted of 108 patients with diabetes mellitus, type II, who visited the medical clinic as outpatients. Data collection took place from March to June 2014. The inclusion criteria were a) having had diabetes for over 2 years b) being over 18 years of age c) having the ability to speak and/or write the Greek language d) attending the diabetic clinic during the study period.

\section{Procedure}

Ethical approval for this research project was obtained from both the Hospital's Scientific Committee and its Ethics Committee. The first author approached all potential participants and explained the purpose of the study. Also, she informed them about the anonymity and confidentiality of the data and the voluntary nature of their participation. Those patients who agreed to participate were asked to provide oral informed consent. The response rate was $92 \%$.

Instruments

Data was collected via a questionnaire consisting of two scales. The first part included questions on socio-demographic characteristics and the second part consisted of two questionnaires, entitled "Diabetes Self-Care Activities Questionnaire", which measures treatment compliance, and the "SF-36 Scale for Measuring Quality of Life".

The Diabetes Self-Care Activities Questionnaire measures treatment adherence among patients with type 2 diabetes. It consists of 38 items and the categories of the questionnaire are: diet, exercise, blood test - blood glucose test, foot care, recommendations for self-care. The instrument was tested on the Greek population and showed sufficient validity, discriminant ability, reliability and sensitivity to change (19). The questionnaire's reliability was satisfactory and Cronbach's alpha was 0.83. (19) In the present study, Cronbach's alpha ranged from 0.77 to 0.91 .

Quality of life was measured using the Short- Form- 36 Health Survey (SF-36). It consists of 36 questions, divided into eight health concepts: physical functioning, physical role, bodily pain, general health, vitality (energy / fatigue), social functioning, emotional role and mental health. These sub scales are divided into two wider sub scales: physical

\begin{tabular}{|c|c|c|}
\hline Gender & $\mathrm{N}$ & $\%$ \\
\hline Men & 51 & 47.2 \\
\hline Women & 57 & 57.8 \\
\hline Marital status & & $\%$ \\
\hline Single & 8 & 7.4 \\
\hline Married & 71 & 65.7 \\
\hline Divorced & 5 & 4.6 \\
\hline Widowed & 20 & 18.5 \\
\hline Unmarried couples & 2 & 1.9 \\
\hline Educational status & & $\%$ \\
\hline Primary school & 46 & 42.6 \\
\hline Middle school & 21 & 19.4 \\
\hline High School & 20 & 18.5 \\
\hline College / University & 15 & 13.9 \\
\hline Masters Degree & 2 & 1.9 \\
\hline Occupational Status & & $\%$ \\
\hline Unemployed & 7 & 6.5 \\
\hline Housekeepers & 21 & 19.4 \\
\hline Civil servants & 9 & 8.3 \\
\hline Private-sector employees & 3 & 2.8 \\
\hline Farmers & 11 & 10.2 \\
\hline Executives & 1 & 0.9 \\
\hline Self-employed professionals & 6 & 5.6 \\
\hline Retired & 55 & 50.9 \\
\hline $\mathrm{BMI}$ & & $\%$ \\
\hline$\square 25$ & 41 & 38.0 \\
\hline $25-36$ & 56 & 51.9 \\
\hline$>35$ & 11 & 10.2 \\
\hline Type of Treatment & & $\%$ \\
\hline Diet & 5 & 4.6 \\
\hline Oral medication & 49 & 45.4 \\
\hline Insulin & 23 & 21.3 \\
\hline Oral medication and insulin & 23 & 21.3 \\
\hline $\mathrm{HbA}_{1} \mathrm{c}$ & & $\%$ \\
\hline$<6.5$ & 24 & 22.2 \\
\hline $6.5-7$ & 33 & 30.6 \\
\hline $7-7.5$ & 19 & 17.6 \\
\hline $7.5-8$ & 12 & 11.1 \\
\hline$>8$ & 7 & 6.5 \\
\hline
\end{tabular}

Table 1. Demographic and Clinical Characteristics 


\begin{tabular}{ll}
\hline Subscales of Adherence Scale & Mean \pm SD \\
\hline Diet & $4 \pm 1.62$ \\
\hline Exercise & $1.67 \pm 1.71$ \\
\hline Blood Test - Blood Glucose Test & $4.98 \pm 2.53$ \\
\hline Foot Care & $2.26 \pm 2.39$ \\
\hline Recommendations on Self-Care & $3.27 \pm 0.93$ \\
\hline Subscales SF-36 & Mean \pm SD \\
\hline Physical Condition & $39.96 \pm 14.87$ \\
\hline Physical Role & $36.98 \pm 17.17$ \\
\hline Physical Pain & $48.79 \pm 11.48$ \\
\hline General Health & $38.95 \pm 11.70$ \\
\hline Vitality & $46.31 \pm 15.87$ \\
\hline Social Functioning & $38.41 \pm 13.51$ \\
\hline Emotional Role & $36.84 \pm 19.72$ \\
\hline Mental Health & $38.24 \pm 15.87$ \\
\hline
\end{tabular}

Table 2. Mean and Standard Deviation of the Subscales in Adherence Questionnaire and SF-36 Questionnaire

\begin{tabular}{llllll}
\hline & Gender ${ }^{*}$ & Age ${ }^{*}$ & $\begin{array}{l}\text { Type of } \\
\text { Treatment }{ }^{* *}\end{array}$ & $\begin{array}{l}\text { Family } \\
\text { Status }{ }^{* *}\end{array}$ & $\begin{array}{l}\text { Level of } \\
\text { Education } \\
{ }^{*}\end{array}$ \\
\hline Diet & 0.814 & 0.822 & 0.214 & 0.807 & 0.289 \\
\hline Exercise & 0.122 & 0.450 & 0.098 & 0.295 & 0.091 \\
\hline $\begin{array}{l}\text { Blood Test- } \\
\text { Blood Glucose } \\
\text { Test }\end{array}$ & 0.285 & 0.979 & 0.000 & 0.849 & 0.937 \\
\hline Foot Care & 0.719 & 0.863 & 0.798 & 0.246 & 0.426 \\
\hline
\end{tabular}

Table 3. Comparison Between Gender, Age, Marital Status, Level of Education, Type of Treatment and Subscales of Adherence Scale. ${ }^{*}$ Mann -Witney test, ${ }^{* *}$ Kruskal-Wallis test

health and mental health (20).

Scores range from 0 to 100, with higher scores indicating better health status. The Greek version of the SF-36 is in an unpublished dissertation (21), which was hereby being tested on a Greek population. Cronbach's alpha in this sample ranged from 0.86 to 0.90 . Demographic characteristics and clinical variables (type of treatment, HbA1c, side effects of diabetes) were obtained from patients' medical records.

\section{Data Analysis}

The statistical software package SPSS-20 was used for the purpose of data analysis. Descriptive statistics were applied for demographic statistics. The data of the present study was not normally distributed, and thus non-parametric tests were performed.

\section{RESULTS}

Patients' characteristics are presented in Table of between 6.5-7 whereas $22.2 \%(n=24)$ had an $\mathrm{HbA1}$ cof $<6.5$.

The vast majority of patients had hypertension (75\%), $34.3 \%$ had vision abnormalities and $27.8 \%$ had depression as comorbidities and $46.3 \%(n=50)$ did not smoke.

Table 2 shows the mean and standard deviation for diabetes adherence questionnaire sub scales. As can be seen, best adherence values relate to diet, blood test-blood sugar tests and recommendations on self-care activities. This table also displays the mean and standard deviation for the SF-36 sub scales. The sub scale scores are mostly in the middle or lower range. The higher scores relate to physical functioning, bodily pain, general health, vitality, social functioning, and mental health, showing that these particular patients were in good health.

The results of the comparison between gender, age, marital status, educational status, type of treatment and sub scales of adherence are presented in Table 3. It is important to emphasize that the only statistically significant difference relates to the difference between blood tests and type of treatment $(\mathrm{p}=0.000)$. Further analysis has shown that this is a difference observed in patients being treated with oral medication by comparison to patients with insulin treatment $(p=0.000)$. Moreover, there is a further statistical difference between patients treated with oral medication and patients treated with a combination of oral medication and insulin ( $\mathrm{p}=0.01)$.

The sub scales of the SF-36 are divided into two general sub scales, i.e. the physical and mental sub scale. These two

\begin{tabular}{|c|c|c|c|c|c|}
\hline \multirow[b]{2}{*}{$\begin{array}{l}\text { Subscales of } \\
\text { SF-36 }\end{array}$} & \multicolumn{5}{|c|}{ Subscales of Adherence Scale } \\
\hline & Diet & Exercise & $\begin{array}{c}\text { Blood } \\
\text { Test- Blood } \\
\text { Glucose Test }\end{array}$ & Foot Care & $\begin{array}{c}\text { Recommen- } \\
\text { dations / } \\
\text { Self-Care }\end{array}$ \\
\hline Physical & 0.368 & -0.347 & 0.405 & -0.229 & -0.133 \\
\hline Functioning & 0.000 & 0.000 & 0.000 & 0.017 & 0.104 \\
\hline \multirow{2}{*}{ Physical Role } & 0.259 & -0.360 & -0.215 & 0.341 & 0.262 \\
\hline & 0.001 & 0.000 & 0.016 & 0.000 & 0.003 \\
\hline \multirow{2}{*}{$\begin{array}{l}\text { Bodily } \\
\text { Pain }\end{array}$} & 0.159 & 0.191 & -0.042 & 0.092 & -0.078 \\
\hline & 0.057 & 0.033 & 0.112 & 0.043 & 0.066 \\
\hline \multirow{2}{*}{ General Health } & -0.392 & 0.360 & 0.450 & 0.247 & 0.326 \\
\hline & 0.000 & 0.001 & 0.000 & 0.011 & 0.001 \\
\hline \multirow{2}{*}{ Vitality } & -0.302 & 0.244 & 0.119 & -0.099 & 0.221 \\
\hline & 0.001 & 0.012 & 0.142 & 0.036 & 0.063 \\
\hline Social & 0.401 & -0.227 & 0.154 & 0.285 & -0.165 \\
\hline Functioning & 0.000 & 0.054 & 0.116 & 0.032 & 0.065 \\
\hline \multirow{2}{*}{ Mental Health } & 0.364 & -0.353 & 0.317 & 0.266 & -0.142 \\
\hline & 0.000 & 0.000 & 0.001 & 0.039 & 0.010 \\
\hline \multirow{2}{*}{ Emotional Role } & -0.127 & 0.279 & -0.313 & 0.155 & -0.228 \\
\hline & 0.001 & 0.008 & 0.001 & 0.017 & 0.016 \\
\hline \multirow{2}{*}{ Total } & 0.244 & 0.408 & -0.218 & 0.349 & 0.240 \\
\hline & 0.016 & 0.000 & 0.014 & 0.000 & 0.009 \\
\hline
\end{tabular}

1. All patients had Greek nationality and their Table 4. Correlations Among Subscales and Short Form-36 Subscales age ranged from 45 to 85 years, with a mean of $66.7 \pm 10.9$ years of age. The majority of patients were women $(n=57$, $57.8 \%)$ and married $(\mathrm{n}=71,65.7 \%)$. Almost half of the sample $(n=46,42.6 \%)$ had primary school education and were retired $(n=55,50.9 \%)$. Many of them $(n=32,29.6 \%)$ had been diagnosed with diabetes $6-10$ years prior to the beginning of the study period, and the vast majority $(n=56,51.9 \%)$ had 25-36 BMI. Most of these subjects $(n=49,45.4 \%)$ were treating their diabetes exclusively with drugs, $21.3 \%(n=23)$ took only injection insulin and $21.3 \%(n=23)$ took oral drugs and injection insulin. Most of them $(n=33,30.6 \%)$ had an HbA1c

sub scales are examined according to demographic and certain clinical characteristics. The comparison of two sub scales with certain clinical characteristics (gender, type of treatment, educational status and marital status) revealed that only marital status affected mental health in terms of a statistically significant difference $(p=0.032)$. Furthermore, there is statistically significant difference in mental health between married and unmarried patients $(p=0.008)$.

Table 4 presents the correlations between the adherence and SF-36 sub scales. As can be seen, the majority of the adherence sub scales are correlated with the majority of SF- 
36 sub scales and this correlation is statistically significant. Furthermore, the sub scales of two scales are well correlated overall ( $\mathrm{p}<0.01)$.

\section{DISCUSSION}

The present study assesses the adherence of Greek diabetes patients to their treatment regimens, as well as the association between adherence and quality of life. It contributes to the growing body of evidence regarding treatment adherence and provides important information to Greek health professionals, since describing this phenomenon is a fundamental step toward appropriate interventions.

The diabetes patients included in this study generally have a good level of adherence. This is consistent with other studies $(13,22)$. Our study reveals that patients showed better adherence to diet and blood glucose tests. This positive result with respect to adherence could be attributed to many factors, such as good communication between patients and healthcare professionals, patients' knowledge about monitoring their condition, their disease and its complications (22).

Therefore, the low level of adherence on exercise and foot care is consistent with other studies. However, Saleh et al examined non-adherence in 500 patients with type II diabetes and found high percentages of non-adherence in blood glucose monitoring, diet, foot care and exercise (23).

It is interesting to see that patients in this study achieved high scores for their adherence with recommendations concerning self-care. This finding can explained by the assumption that many patients wish to acquire knowledge and abilities in order to control their disease, to prevent complications and improve their quality of life (24).

The results of this study have shown that adherence levels are similar in male and female patients and no statistical difference between adherence and age was observed. These findings are similar to those of other studies $(13,22)$. Moreover, patients' level of education did not affect adherence, although this finding is inconsistent with other studies (25) which found that educational status was associated with non-adherence. This discrepancy can be explained by the fact the studies used different methodologies and different sample sizes.

Furthermore, the present study shows that adherence to type blood exams is different according to type of treatment. This means that patients who were taking only oral drugs showed better adherence than patients using only insulin injection and patients using a combination of oral drugs and insulin injections. This result is consistent with other studies, in which patients who took insulin or a combination of drugs had a high percentage of non - adherence to their treatment $(25,26)$.

The mean quality of life scores for the different domains ranged from 36.98 to 48.79 . This can be explained by the fact that we selected patients with complications and therefore their quality of life may have been underestimated because it is affected by these (18). When we compare our study with the results of other studies $(18,23)$ we observe differences between the scores experienced by the study samples. This is an expected outcome because the other studies used a different questionnaire for assessing quality of life, different sample sizes and patients without complications (18). Also, because of the nature of this chronic disease, a decline in quality of life (27) is to be expected.

Marital status was the only sociodemographic variable is linked to the mental health domain of quality of life. This is in line with the results of other studies, which have found that factors such as age, educational and marital status affect quality of life (27).

The association between most of the quality of life domains and the sub scales of adherence is consistent with the results of other studies $(15,16,17)$. As mentioned above, there are conflicting results regarding this link, which emphasized the need for more studies to use the same scales in order to arrive at reliable results and help patients to increase treatment adherence and quality of life.

The present study has some limitations. One of these is that the study was conducted as only one provincial hospital in Northern Greece, and thus our results cannot be generalized with respect to Greek diabetes patients. Another limitation is that we used a convenience sample and the sample collection was conducted over a brief period of time. Nonetheless, since this is the very first Greek study on this topic, we believe that the results are worth sharing with the research community.

\section{CONCLUSIONS}

In this study we identified that diabetes patients adhered to diet, blood test exams and advice regarding self-care. We recognized that there is a link between quality of life and adherence to treatment. Based on these results, we consider it is important to plan interventions to enhance adherence to other types of treatment and thereby help these patients to further improve their quality of life. To this end appropriate patient education and patient / health professional relationships should be established. In conclusion, more studies will be required in order to provide a more complete picture of the relation between adherence and quality of life.

Conflict of interest: none declared.

\section{REFERENCES}

1. Gusmai Lde F, Novato Tde S, Nogueira Lde S. The influence of quality of life in treatment adherence of diabetic patients: a systematic review. Rev Esc Enferm USP. 2015 ; 49(5): 839-46.

2. Diabetes. World Health Organization 2016.available at www.who.into access 20/2/2016

3. Tentolouris N, Andrianakos A, Karanikolas G. et al. Prevalence of diabetes mellitus and obesity in the general adult population of Greece: a door-to-door epidemiological study. Diabet Med. 2009; 26: 451-2.

4. Adherence to long-term therapies. Evidence for action. World Health Organization 2003. Available at www. who.into access 20/2/2016

5. Chew BH,HassanNH, Sherina MS. Determinants of medication adherence among adults with type 2 diabetes mellitus in three Malaysian public health clinics: a cross-sectional study. Patient Prefer Adherence. 2015 6; 9: 639-48.

6. Xin C, Xia Z, Jiang C, Lin M, Li G. Effect of phar- 
maceutical care on medication adherence of patients newly prescribed insulin therapy: a randomized controlled study. Patient Prefer Adherence. 2015 18; 9: 797-802.

7. Cramer JA. A systematic review of adherence with medications for diabetes. Diabetes Care. 2004, 27(5): 1218-24.

8. Kleefstra N, Ubink-Veltmaat LJ, Houweling ST, Groenier KH, Meyboom-de Jong B, Bilo HJ. Cross- sectional relationship between glycaemic, hyperglycaemic symptoms and quality of life in type 2diabetes (ZODIAC-2). Neth J Med. 2005; 63(6): 215-21.

9. WHOQOL. Measuring quality of life available at www. who.int access 20/4/2016

10. Jackson IL, Adibe MO, Okonta MJ, Ukwe CV. Medication adherence in type 2 diabetes patients in Nigeria. Diabetes Technol Ther. 2015; 17(6): 398-404. doi: 10.1089/ dia.2014.0279.

11. Gonzalez JS, Safren SA, Delahanty LM, Cagliero E, Wexler DJ, Meigs JB, Grant RW. Symptoms of depression prospectively predict poorer self-care in patients with Type 2 diabetes. Diabet Med. 2008; 25(9): 1102-7. doi: 10.1111/j.1464-5491.2008.02535.x.

12. Miller TA, Dimatteo MR. Importance of family/social support and impact on adherence to diabetic therapy. Diabetes Metab Syndr Obes. 2013; 6 (6),421-6.

13. McAdam-Marx C, Bellows BK, Unni S, Wygant G, Mukherjee J, Ye X, Brixner DI. Impact of adherence and weight loss on glycemic control in patients with type 2 diabetes: cohort analyses of integrated medical record, pharmacy claims, and patient-reported data. J Manag Care Spec Pharm. 2014; 20(7): 691-700.

14. Saleem F, Hassali MA, Shafie AA, Awad GA, Atif M, ul Haq N, Aljadhey H, Farooqui M. Does treatment adherence correlates with health related quality of life? Findings from a cross sectional study. BMC Public Health. 2012 30; 12: 318. doi: 10.1186/1471-2458-12-318.

15. Chaveepojnkamjorn W, Pichainarong N, Schelp FP, Mahaweerawat U. Quality of life and compliance among type 2 diabetic patients. Southeast Asian J Trop Med Public Health. 2008; 39(2): 328-34.

16. Honish A, Westerfield W, Ashby A, Momin S, Phillippi R. Health-related quality of life and treatment compliance with diabetes care. Dis Manag. 2006; 9(4): 195-200.

17. Shim YT, Lee J, Toh MP, Tang WE, Ko Y. Health-related quality of life and glycaemic control in patients with
Type 2 diabetes mellitus in Singapore. Diabet Med. 2012; 29(8): e241-8. doi: 10.1111/j.1464-5491.2012.03689.x.

18. Martínez YV, Prado-Aguilar CA, Rascón-Pacheco RA, Valdivia-Martínez JJ. Quality of life associated with treatment adherence in patients with type 2 diabetes: a cross-sectional study. BMC Health Serv Res. 2008; 30(8): 164. doi: 10.1186/1472-6963-8-164.

19. Intas $G$, Kalogianni A, Stergiannis $P$, Bratakos $M$, Dimoula I, Kelesi M, Vezyridis P, Charalampidis V, Marvaki C. Development and validation of a diabetes self-care activities questionnaire. Journal of Diabetes Nursing. 2012; 16(3): 100-10.

20. Ware JE . SF-36 Health Survey update. Spine. 2000; 25 (24): 3130-9.

21. Sarris M. Quality of life in renal patients. National and Kapodistrian University of Athens, Athens, Greece, 1999.

22. Jimmy B, Jose J, Al-Hinai ZA, Wadair IK, Al-Amri GH. Adherence to Medications among Type 2 Diabetes Mellitus Patients in Three Districts of Al DakhliyahGovernorate, Oman: A cross-sectional pilot study. Sultan Qaboos Univ Med J. 2014 ; 14(2): e231-5.

23. Saleh F, Mumu SJ, Ara F, Hafez MA, Ali L. Non-adherence to self-care practices \& medication and health related quality of life among patients with type 2diabetes: a cross-sectional study. BMC Public Health. 2014; 7(14): 431. doi: 10.1186/1471-2458-14-431

24. Hellenic Diabetes Association. Guidelines for management of diabetic patient. ( 2013). Available at www.ede. gr, access on 22/4/2016

25. Khan AR, Al-Abdul Lateef ZN, Al Aithan MA, BuKhamseen MA, Al Ibrahim I, Khan SA. Factors contributing to non-compliance among diabetics attending primary health centers in the Al Hasa district of Saudi Arabia. J Family Community Med. 2012; 19: 26-32. doi: 10.4103/2230-8229.94008.

26. Donnelly LA, Morris AD, Evans JM. DARTS/MEMO collaboration. Adherence to insulin and its association with glycaemic control in patients with type 2 diabetes. QJM. 2007; 100(6): 345-50.

27. Nazir SU, Hassali MA, Saleem F, Bashir S, Hashmi F, Aljadhey H. A cross-sectional assessment of healthrelated quality of life among type 2 diabetic patients in Pakistan. J Pharm Bioallied Sci. 2016; 8(1): 64-8. doi: 10.4103/0975-7406.171734. 